\title{
Thrombopoietin Receptor Agonists Are Often Ineffective in Immune Thrombocytopenia and/or Cause Adverse Reactions: Results from One Hand
}

\author{
Fabian Depré Nasra Aboud Frauke Ringel Abdulgabar Salama \\ Institute for Transfusion Medicine, Charité - Universitätsmedizin Berlin, Berlin, Germany
}

\section{Keywords}

Autoimmune thrombocytopenia · Eltrombopag . Romiplostim · Thrombopoietin receptor agonists . Adverse reactions

\section{Summary}

Background: Eltrombopag and romiplostim are thrombopoietin receptor agonists (TPOs) that have been increasingly used for the treatment of immune thrombocytopenia (ITP). Based on our experience, the incidence of abortive treatment with these drugs and the occurrence of adverse reactions that lead to therapy break-off despite response are higher than has been previously suggested. Methods: During the last 8 years, a total of 65 patients were treated with eltrombopag and/or romiplostim at our institute. Results: 36 of a total of 58 patients responded well to eltrombopag. In 12 patients that responded, treatment with eltrombopag was discontinued due to the development of adverse reactions. Eltrombopag was replaced by romiplostim in 23 cases (14 non-responders, 9 patients with adverse reactions). Of these patients, $83 \%$ responded to romiplostim. Among all patients treated with romiplostim ( $n=32$ ), $75 \%$ initially responded; however, 8 of these patients developed adverse reactions. Romiplostim was replaced by eltrombopag in 5 cases ( 4 due to adverse reactions, 1 non-responsive patient), and only $3(60 \%)$ of these patients were observed to respond to eltrombopag. Conclusion: TPOs often remain ineffective in ITP or result in adverse reactions, which lead to treatment stop or to drug switch. Therefore, alternative treatment options are required.

(C) 2016 S. Karger GmbH, Freiburg

\section{Introduction}

Immune thrombocytopenia (ITP) remains one of the best characterized human autoimmune diseases. Although some other mechanisms might be involved, it mainly results from the production of autoantibodies against platelet antigens and thereby from the premature destruction of platelets [1]. Treatment is required at least in cases where the affected patients develop bleeding or a bleeding risk. However, none of the currently available therapies, including corticosteroids, intravenous high-dose immunoglobulin G (IVIG), anti-D, rituximab, splenectomy or immunosuppressive drugs, are invariably effective, and a good response (platelet counts $>50,000 / \mu \mathrm{l}$ ) cannot be predicted in a single native, untreated patient. Furthermore, current standard therapies are unspecific and are largely based on selective or unselective immunosuppression [2-5].

During the last decade, the thrombopoietin receptor agonists (TPOs) romiplostim and eltrombopag have been increasingly used in the treatment of patients with ITP. Several well designed multicenter studies [6-13] have demonstrated an increase in platelet counts in the majority of enrolled patients. Treatment with both drugs is generally effective, safe, and the majority of side effects observed are mild. However, the aforementioned studies involved a somewhat selective study population and a relatively small number of patients. Meanwhile, it became obvious that both drugs may indeed cause, at least in isolated cases, severe or even dangerous adverse reactions, including thromboembolic events, arthralgias, increase of bone marrow fibrosis, and myeloproliferative neoplasias [6-13].

\section{KARGER}

() 2016 S. Karger GmbH, Freiburg

Fax +497614520714 
Table 1. Patient and clinical characteristics

\begin{tabular}{ll}
\hline Patients, $\mathrm{n}$ & 65 \\
Mean age (range), years & $55(18-87)$ \\
Gender (m/f) & $25 / 40$ \\
ITP diagnosis, year (range) & $2006(1981-2014)$ \\
Primary/secondary ITP & $61 / 4^{+}$ \\
Patients treated with romiplostim & 32 \\
First TPO & 10 \\
$\quad$ After treatment with eltrombopag & $23^{\star}$ \\
$\quad$ Mean treatment duration (range), months & 14.7 (1-75) \\
Patients treated with eltrombopag & 58 \\
$\quad$ First TPO & 55 \\
$\quad$ After treatment with romiplostim & $5^{* *}$ \\
$\quad$ Mean treatment duration (range), months & $16,8 / 1-60$ \\
\hline & \\
& Initially was diagnosed as primary form. \\
$* 1$ patient switched from romiplostim to eltrombopag and back to romiplostim. \\
$*$ 2 patients switched from eltrombopag to romiplostim and back to eltrom- \\
$\quad$ bopag.
\end{tabular}

Table 2. Therapies prior to treatment with thrombopoietin receptor agonists

\begin{tabular}{lc}
\hline Previous therapies & Patients, $\mathrm{n}$ \\
\hline Prednisolone, IVIG, azathioprine & 7 \\
Prednisolone, azathioprine & 5 \\
Prednisolone, IVIG & 5 \\
Prednisolone & 4 \\
No prior therapy & $4^{+}$ \\
Prednisolone, azathioprine, IVIG, platelet concentrate & 2 \\
Prednisolone, IVIG, rituximab, dexamethasone, anti-D & 2 \\
Prednisolone, IVIG, dexamethasone, anti-D & 2 \\
Prednisolone, azathioprine, dexamethasone & 2 \\
Prednisolone, azathioprine, IVIG, dexamethasone, anti-D & 2 \\
Prednisolone, anti-D & 1 \\
IVIG, anti-D & 1 \\
Different combinations of 3-7 drugs ${ }^{*} \pm$ Splx & 28 \\
\cline { 2 - 2 } Total & 65 \\
\hline
\end{tabular}

Splx = splenectomy.

${ }^{+} 2$ patients with hepatic cirrhosis, 1 patient with hepatitis C , 1 patient with HIV and hepatitis C.

*Including prednisolone, azathioprine, dexamethasone, rituximab, anti-D, mycophenolate-mofetil, cyclophosphamide, ciclosporine, IVIG, platelet concentrate, danazol, spanidin.
Table 3. Adverse reactions that led to discontinuation of TPOs despite response

\begin{tabular}{lll} 
& eltrombopag & romiplostim \\
\hline Arthritis & 5 & 4 \\
Diarrhea / abdominal pain & 2 & - \\
Exanthema & 1 & - \\
Stroke & - & 1 \\
Nausea / sudden hearing loss & - & 1 \\
Thoracic pain & - & 1 \\
Vision impairment & - & 1 \\
Chronic myeloproliferative disease ${ }^{+}$ & 1 & - \\
Headache & 1 & - \\
Myalgia & 1 & - \\
Hair loss & 1 & - \\
\hline${ }^{+}$Relation to the drug remains unclear. & & \\
\hline
\end{tabular}

\section{Results}

Until May 2015, we gave attention to 58 patients treated with eltrombopag and 32 patients treated with romiplostim. Treatment was initially commenced with eltrombopag in 55 and with romiplostim in 10 cases (table 1). During observation, several patients developed adverse reactions, or the medication remained ineffective despite dose escalation to 75 or even $100 \mathrm{mg} /$ day eltrombopag or to $10 \mu \mathrm{g} / \mathrm{kg}$ romiplostim. All patients that did not show response to TPOs were further treated with immunosuppressive drugs or received splenectomy (fig. 1, 2).

Treatment with TPOs resulted in compensated primary hemostasis and an increase in platelet counts to $>50,000 / \mu l$ during observation in 36 of 58 patients (62\%) receiving eltrombopag and in 24 of 32 patients $(75 \%)$ treated with romiplostim.

Twelve responding patients treated with eltrombopag discontinued the treatment due to adverse reactions (fig. 1, table 3) that occurred between 1 and 20 months after treatment initiation. The adverse reaction became tolerable in 1 patient after dose reduction of eltrombopag. In comparison, treatment with romiplostim was discontinued in 8 patients due to adverse reactions that occurred between 1 and 66 months after treatment initiation with romiplostim (fig. 2, table 3). In addition, 11 patients discontinued the treatment with eltrombopag due to remission (normalization of platelet counts without any therapy; $n=4)$, lack of drug $(n=3)$, refusal by patient $(n=3)$, and pregnancy $(n=1)$. Similary, 3 other patients discontinued treatment with romiplostim due to lack of drug $(n=1)$, refusal by patient $(n=1)$, and splenomegaly $(n=1)$. So far, 14 of 58 patients (24\%) treated with eltrombopag continued treatment (fig. 1), whereas 15 of 32 patients (47\%) treated with romiplostim continued treatment (fig. 2).

Eltrombopag was directly (with no wash-out phase) replaced by romiplostim in 9 of the 12 patients with adverse reactions and in 11 of the 22 non-responsive patients. Three unresponsive patients received romiplostim following splenectomy. In total, 23 patients replaced eltrombopag by romiplostim. All of the eltrombopag-responsive patients that changed therapy due to adverse reactions 


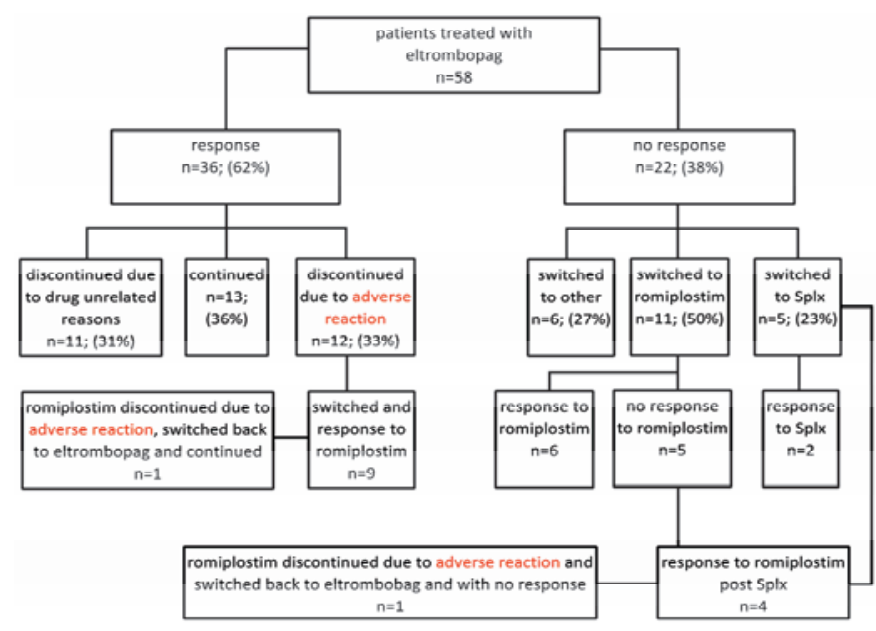

Fig. 1. Course of treatment in patients with immune thrombocytopenia receiving eltrombopag, initially or after switching. Splx = splenectomy.

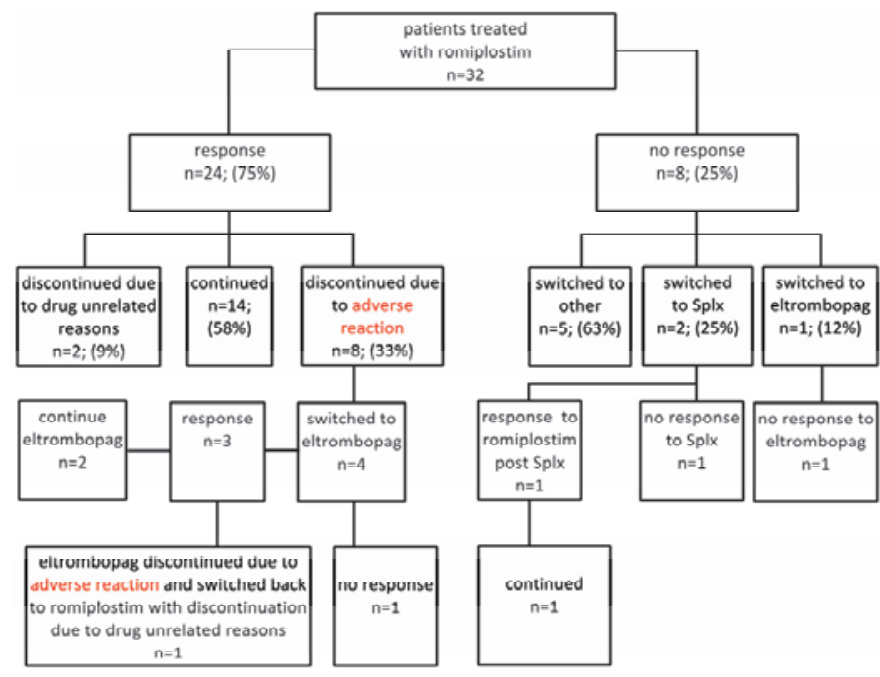

Fig. 2. Course of treatment in patients with immune thrombocytopenia receiving romiplostim, initially or after switching. Splx = splenectomy.
Table 4. Switched patients and reasons for switching to the alternate TPO

\begin{tabular}{lrrlll}
\hline Switch to & Total & Response & \multicolumn{2}{l}{ Reasons for switching / response thereafter } & \multirow{2}{*}{$\begin{array}{l}\text { patients with adverse } \\
\text { reactions prior/after }\end{array}$} \\
\cline { 3 - 5 } & & & lack of efficacy & adverse reactions & $16\left(^{*}\right) / 5$ \\
\hline Romiplostim & 23 & $19(83 \%)$ & $14 / 10^{+}(71 \%)$ & $9 / 9(100 \%)$ & $4 / 3$ \\
Eltrombopag & 5 & $3(60 \%)$ & $1 / 0(0 \%)$ & $4 / 3(75 \%)$ & \\
\hline
\end{tabular}

were observed to respond well to romiplostim too, whereas only 6 of the 11 eltrombopag non-responders were observed to directly respond to romiplostim (fig. 1, table 4). All 3 patients that underwent splenectomy responded to romiplostim. One patient did not respond to romiplostim prior to splenectomy, but thereafter. In total, 19 of the 23 switched patients responded to romiplostim (table 4). During observation, 5 of the 19 responding patients developed adverse reactions to romiplostim (table 4). Seven of the eltrombopag responders with adverse reactions could be safely treated with romiplostim, and the remaining 2 patients also showed adverse reactions to romiplostim. In comparison, romiplostim was replaced by eltrombopag in 4 cases due to adverse reactions and in one case due to non-effectivity (table 4). Three of the former patients responded well to eltrombopag, whereas the latter patient did not respond to eltrombopag (table 4). Three of the 5 switched patients developed adverse reactions to eltrombopag, and 2 of the responding patients with adverse reactions could be safely treated with eltrombopag.

Seven patients were splenectomized prior to treatment with eltrombopag. Four of these patients responded to the drug, and 3 did not respond. Ten patients had a history of splenectomy prior to treatment with romiplostim. Six of these patients responded to the drug, and 4 did not respond. Three of the splenectomized romiplostim patients had been refractory to eltrombopag before splenectomy and responded to romiplostim post splenectomy.
In conclusion, treatment with eltrombopag and/or romiplostim was effective and continued under observation in 29 of 65 (45\%) cases.

\section{Discussion}

Previous well designed, randomized and controlled studies have demonstrated, that TPOs are not only highly effective but also largely safe in the treatment of ITP [6 -13]. They showed response rates of $65-92 \%$ for romiplostim and of $57-88 \%$ for eltrombopag. The most frequent adverse reactions reported in those studies were considered to be mild to moderate reactions including headache, fatigue, arthralgia, myalgia, and gastrointestinal disorders. The frequencies of severe adverse reactions, e.g. thromboembolic events, bone marrow reticulin transformation or development of myeloproliferative diseases, were reported to be between 0 and $15 \%$. However, 3 long-term (2-5 years) studies dealing also with the discontinuation rate caused by adverse reactions showed a drop-out rate of $3-4 \%$ for romiplostim, and of $13 \%$ for eltrombopag [10, 12 , 13]. Moreover, an indirect comparison between patients who received TPOs for 24-26 weeks has demonstrated an overall durable response rate of $42 \%$ for eltrombopag and $49 \%$ for romiplostim [25]. More importantly, the increase of bone marrow fibrosis appears to be higher $(20-31 \%)$ than has been suggested [26, 27]. 
Table 5. All adverse reactions occurred during observation period ${ }^{+}$

\begin{tabular}{lll} 
& Eltrombopag & Romiplostim \\
\hline Arthralgia & 8 & 5 \\
Diarrhea / abdominal pain & 4 & - \\
Nausea & 3 & 1 \\
Myalgia & 3 & 2 \\
Stroke & - & 2 \\
Thrombosis & 3 & - \\
Exanthema & 3 & 2 \\
Hair loss & 2 & - \\
Cramps & 2 & - \\
Renal failure & - & 1 \\
Chronic myeloproliferative disease* & 1 & - \\
T-cell lymphoma & 1 & - \\
Fatigue & 1 & - \\
Thoracic pain & - & 1 \\
Bone pain & 1 & - \\
Splenomegaly & 1 & - \\
Headache & 1 & - \\
Weight loss & 1 & - \\
Angina pectoris & 1 & - \\
Vision impairment & - & \\
Sudden hearing loss & - & \\
\hline${ }^{*}$ Occurred in responding and non-responding patients, including patients with \\
more than one adverse reaction. & & \\
${ }^{*}$ Relation to the drug remains unclear. & & - \\
& & \\
& & \\
& &
\end{tabular}

Nevertheless, utilization of both drugs is increasing on a global scale. Our observational study presents data of patients treated from one hand. Compared with pivotal studies, our results show slight differences regarding the efficacy and adverse reactions of TPOs. The efficacy does not appear to be as high as previously suggested, and adverse reactions were found to occur more frequently than previously reported. One possible explanation for this discrepancy may be related to errors in statistical analyses which may occur in any medical research [14-16]. Previous studies dealing with patients treated with TPOs and placebo were more focused on platelet counts rather than on the clinical picture of the affected patients. In contrast, our study focused on the clinical course of each patient prior, during and after the treatment with eltrombopag and romiplostim. Thus, the occurrence of any adverse reaction during observation could be exactly characterized. With the exception of 2 patients that developed myeloproliferative diseases, all other adverse reactions observed in the patients reported here, abolished within a few days or weeks after cessation or replacement of the causative drug. In contrast, previous reports of adverse reactions in ITP patients may be easily misinterpreted. For example, fatigue is now a well-characterized phenomenon in ITP. We and others [17-19] have observed that fatigue predominantly occurs when platelet counts decrease to $<50,000 / \mu$ in most affected patients. Comparison of adverse reactions in patients either receiving drugs or a placebo has demonstrated that the difference between both groups is insignificant. In those studies, the correlation between fatigue and platelet counts has not been assessed [6, 9]. In our experience, arthralgia is a typical symptom observed in isolated cases of ITP. Fatigue and/or arthralgia often occur only when the platelet count is $<50,000 / \mu \mathrm{l}$. An immediate improvement of both symptoms is observed when platelet counts increase, spontaneously or by any therapy. Therefore, the data reported in pivotal studies regarding fatigue and arthralgia are, as we believe, not valid as platelet counts were not considered in affected cases. If we assume that the adverse reactions observed in our patients are indicative of true adverse reactions, treatment with TPOs resulted in adverse reactions in at least $33 \%$ of patients receiving eltrombopag (19 of 58 patients, table 5) and in 34\% receiving romiplostim (11 of 32 patients, table 5). Regarding the responsive patients, treatment with TPOs resulted in adverse reactions at least in 33\% for eltrombopag ( 12 of 36 patients, table 3 ) and $32 \%$ receiving romiplostim ( 8 of 25 patients, table 3 ). Ultimately, in some patients who tolerate therapy, adverse reactions may develop over time. In addition, regular biopsies to exclude the development of bone marrow fibrosis as has been recommended $[7,13,20]$ were not performed. Therefore, the true incidence of adverse reactions may be higher than has been observed so far.

As observed in our and in other studies [21-24], switching between TPOs appears to be beneficial in regard to efficacy and adverse reactions; nevertheless, some patients remained refractory to both drugs ( 5 of 25 patients). Furthermore, adverse reactions cannot invariably be overcome by switching. This was observed in 2 patients in this study. One of these patients developed a severe skin rash that diminished by discontinuation of romiplostim and was re-stimulated by eltrombopag. In another patient treatment with both drugs resulted in significant arthralgia.

Based on our results with TPOs, we highly recommend a strict and continuous surveillance throughout the course of treatment as necessary. Treatment with TPOs has been demonstrated to result in an increased risk of severe or life-threatening adverse drug reactions. Furthermore, long-term data are still lacking.

As the available TPOs do not cure patients with ITP, a reconsideration of current therapies should be made, and focus should be turned to the development of more specific therapies, not only for ITP but also for other autoimmune diseases.

\section{Disclosure Statement}

All authors declare that they have no conflict of interests due to sponsorship or funding arrangements related to this study. 


\section{References}

1 Cines DB, Liebman HA: The immune thrombocytopenia syndrome: a disorder of diverse pathogenesis and clinical presentation. Hematol Oncol Clin North Am 2009;23:1155-1161.

2 Godeau B, Provan D, Bussel J: Immune thrombocytopenic purpura in adults. Curr Opin Hematol 2007; 14 535-556.

3 Rodeghiero F, Stasi R, Gernsheimer T, Michel M, Provan D, Arnold DM, Bussel JB, Cines DB, Chong BH, Cooper N, Godeau B, Lechner K, Mazzucconi MG, McMillan R, Sanz MA, Imbach P, Blanchette V, Kühne T, Ruggeri M, George JN: Standardization of terminology, definitions and outcome criteria in immune thrombocytopenic purpura of adults and children: report from an international working group. Blood 2009; 113:2386-2393

4 Provan D, Stasi R, Newland AC, Blanchette VS, Bolton-Maggs P, Bussel JB, Chong BH, Cines DB, Gernsheimer TB, Godeau B, Grainger J, Greer I, Hunt BJ, Imbach PA, Lyons G, McMillan R, Rodeghiero F, Sanz MA, Tarantino M, Watson S, Young J, Kuter DJ: International consensus report on the investigation and management of primary immune thrombocytopenia. Blood 2010;115:168-186.

5 Salama A: Current treatment options for primary immune thrombocytopenia. Expert Rev Hematol 2011;4: 107-118.

6 Kuter DJ, Bussel JB, Lyons RM, Pullarkat V, Gernsheimer TB, Senecal FM, Aledort LM, George JN, Kessler CM, Sanz MA, Liebman HA, Slovick FT, de Wolf JT, Bourgeois E, Guthrie TH Jr, Newland A, Wasser JS, Hamburg SI, Grande C, Lefrère F, Lichtin AE, Tarantino MD, Terebelo HR, Viallard JF, Cuevas FJ, Go RS, Henry DH, Redner RL, Rice L, Schipperus MR, Guo DM, Nichol JL: Efficacy of romiplostim in patients with chronic immune thrombocytopenic purpura: a double-blind randomised controlled trial. Lancet 2008; 371:395-403.

7 Bussel JB, Kuter DJ, Pullarkat V, Lyons RM, Guo M, Nichol JL: Safety and efficacy of long-term treatment with romiplostim in thrombocytopenic patients with chronic ITP. Blood 2009;113:2161-2171. Erratum in Blood 2009;113:4822.

8 Kuter DJ, Rummel M, Boccia R, Macik BG, Pabinger I, Selleslag D, Rodeghiero F, Chong BH, Wang X, Berger DP: Romiplostim or standard of care in patients with immune thrombocytopenia. N Engl J Med 2010;363: 1889-1899.

9 Cheng G, Saleh MN, Marcher C, Vasey S, Mayer B, Aivado M, Arning M, Stone NL, Bussel JB: Eltrombopag for management of chronic immune thrombocytopenia (RAISE): a 6-month, randomised, phase 3 study. Lancet 2011;377:393-402.
10 Khellaff M, Michel M, Quittet P, Viallard JF, Alexis M, Roudot-Thoraval F, Cheze S, Durand JM, Lefrère F, Galicier L, Lambotte O, Panelatti G, Slama B, Damaj G, Sebahoun G, Gyan E, Delbrel X, Dhedin N, Royer B, Schleinitz N, Rossi JF, Mahévas M, Languille L, Bierling P, Godeau B: Romiplostim safety and efficacy for immune thrombocytopenia in clinical practice: 2-year results of 72 adults in aromiplostim compassionate-use program. Blood 2011;118:4338-4345.

11 Bussell JB, Buchanan GR, Nugent DJ, Gnarra DJ, Bomgaars LR, Blanchette VS, Wang YM, Nie K, Jun S: A randomized, double-blind study of romiplostim to determine its safety and efficacy in children with immune thrombocytopenia. Blood 2011;118:28-36.

12 Kuter DJ, Bussel JB, Newland A, Baker RI, Lyons RM, Wasser J, Viallard JF, Macik G, Rummel M, Nie K, Jun S: Long-term treatment with romiplostim in patients with chronic immune thrombocytopenia: safety and efficacy. Br J Haematol 2013;161:411-423.

13 Saleh MN, Bussel JB, Cheng G, Meyer O, Bailey CK, Arning M, Brainsky A; EXTEND Study Group: Safety and efficacy of eltrombopag for treatment of chronic immune thrombocytopenia: results of the long-term, open-label EXTEND study. Blood 2013;121:537-545.

14 Zinsmeister AR, Connor JT: Ten common statistical errors and how to avoid them. Am J Gastroenterol 2008;103:262-266.

15 Strasak AM, Zaman Q, Pfeiffer KP, Göbel G, Ulmer H: Statistical errors in medical research - a review of common pitfalls. Swiss Med Wkly 2007;137:44-49.

16 Bengston WF, Moga M; Resonance, Placebo effects, and type II errors: some implications from healing research for experimental methods. J Altern Complement Med 2007;13:317-327.

17 Newton JL, Reese JA, Watson SI, Vesely SK, BoltonMaggs PH, George JN, Terrell DR: Fatigue in adult patients with primary immune thrombocytopenia. Eur J Haematol 2011;86:420-429.

18 Hill QA, Newland AC: Fatigue in immune thrombocytopenia. Br J Haematol 2015;170:141-149.

19 Matzdorff AC, Arnold G, Salama A, Ostermann H, Eberle S, Hummler S: Advances in ITP-therapy and quality of life-a patient survey. PLoS One 2011; 6:e27350.

20 Ghanima W, Geyer JT, Lee CS, Boiocchi L, Imahiyerobo AA, Orazi A, Bussel JB: Bone marrow fibrosis in 66 patients with immune thrombocytopenia treated with thrombopoietin-receptor agonists: a singlecenter, long-term follow-up. Haematologica 2014;99: 937-944.
1 Kuter DJ, Macahilig C, Grotzinger KM, Poston SA Wang PF, Dawson KL, Ward M: Treatment patterns and clinical outcomes in patients with chronic immune thrombocytopenia (ITP) switched to eltrombopag or romiplostim. Int J Hematol 2015;101:255263

22 González-Porras JR, Mingot-Castellano ME, Andrade MM, Alonso R, Caparrós I, Arratibel MC, FernándezFuertes F, Cortti MJ, Pascual C, Sánchez-González B, Bernat S, Fuertes-Palacio MA, Vázquez-Paganini JA, Olivera PE, Alvarez-Román MT, Jarque I, Cortés M, Martínez-Robles V, Díaz-Gálvez FJ, Calbacho M, Fernández-Miñano C, Garcia-Frade J, González-López TJ: Use of eltrombopag after romiplostim in primary immune thrombocytopenia. Br J Haematol 2015;169: 111-116.

23 Tsukamoto S, Nakaseko C, Takeuchi M, Kumagai K, Komatsu T, Tanaka H, Hara S, Koizumi M, Imai H, Yokota A, Takeuchi M, Inokuchi K, Matsuura Y, Aotsuka N, Wakita H: Safety and efficacy of romiplostim in patients with eltrombopag-resistant or -intolerant immune thrombocytopenia. Br J Haematol 2013;163: 286-289.

24 Khellaf M, Viallard JF, Hamidou M, Cheze S, RoudotThoraval F, Lefrere F, Fain O, Audia S, Abgrall JF, Michot JM, Dauriac C, Lefort S, Gyan E, Niault M, Durand JM, Languille L, Boutboul D, Bierling P, Michel $\mathrm{M}$, Godeau B: A retrospective pilot evaluation of switching thrombopoietic receptor-agonists in immune thrombocytopenia. Haematologica 2013;98: 881-887.

25 Cooper KL, Fitzgerald P, Dillingham K, Helme K, Akehurst R: Romiplostim and eltrombopag for immune thrombocytopenia: methods for indirect comparison. Int J Technol Assess Health Care 2012;28:249-258.

26 Ghanima W, Geyer JT, Lee CS, Boiocchi L, Imahiyerobo AA, Orazi A, Bussel JB: Bone marrow fibrosis in 66 patients with immune thrombocytopenia treated with thrombopoietin-receptor agonists: a singlecenter, long term follow up. Haematologica 2014;99: 937-944.

27 Rizvi H, Butler T, Calaminici M, Doobaree IU, Nandigam RC, Bennett D, Provan D, Newland AC: United Kingdom immune thrombocytopenia registry: retrospective evaluation of bone marrow fibrosis in adult patients with primary immune thrombocytopenia and correlation with clinical findings. Br J Haematol 2015; 169:590-594. 